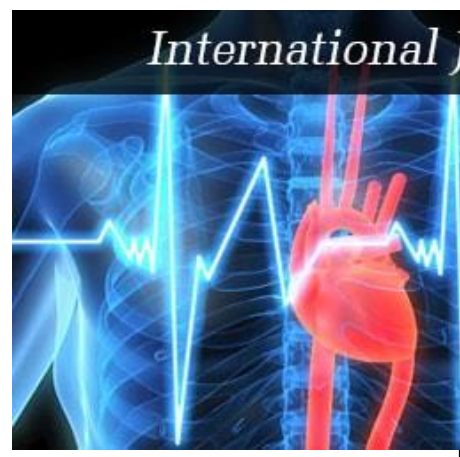

ISSN: 2456-0057

IJPNPE 2021; 6(2): 74-77

(C) 2021 IJPNPE

www.journalofsports.com

Received: 14-05-2021

Accepted: 18-06-2021

\section{Raveendra Khot}

Research Scholar, Visvesvaraya

Technological University,

Belagavi, Karnataka, India

\section{Dr. AG Bujurke}

Research Guide, Director of

Physical Education,

Visvesvaraya Technological

University, Belagavi,

Karnataka, India
Corresponding Author:

Raveendra Khot

Research Scholar, Visvesvaraya

Technological University,

Belagavi, Karnataka, India

\section{A study on emotional intelligence among inter- collegiate badminton men and women players}

\author{
Raveendra Khot and Dr. AG Bujurke
}

DOI: https://doi.org/10.22271/journalofsport.2021.v6.i2b.2285

\section{Abstract}

Badminton is a sport that can be played in a variety of ways. It necessitates a high level of physical fitness. Badminton is a fast-paced movement sport. It is a physically demanding sports wherein Volatile movements will be required for the competitive game. The level of emotional intelligence will be identified among the intercollegiate badminton players. The existing study aims to evaluate intercollegiate badminton players' level of emotional intelligence. To measure emotional intelligence among inter-collegiate players. To see the difference of emotional intelligence between male and female. In essence, the research design was descriptive. The sample consisted 73 badminton players. Inventory for emotional intelligence by Dr. S.K. Mangal and Mrs. Shubhra Mangal was used for measuring emotional intelligence of participants. The majority ( 57.5 percent) of the badminton player's age cohort is $19-21$ years. 52.1 percent of the male badminton players were participated the present study. 69.9 percent of the respondents are from nuclear family. 16.4 percent of the respondents are from B.Com, BA, and MPED background are participated in the present study. 68.5 percent of the respondent's emotional intelligence level is above average. People with higher EIs have been generally recognized as having a higher degree of mental health, success and leadership. Under reality, the major skill for controlling emotions in stressful conditions seems to be having high EI.

Keywords: emotional intelligence, badminton, physical fitness, performance and controlling

\section{Introduction}

Badminton is a sport that can be played in a variety of ways. It necessitates a high level of physical fitness. Badminton is a fast-paced movement sport. It is a physically demanding sports wherein Volatile movements will be required for the competitive game. One cannot utilize the efficiency of the technical and tactical factors, as they are important unless he has an adequate or optimal level of physical fitness. The game necessitates a tremendous amount of alertness, rapidness, endurance, spontaneous effect and accurateness (Wakradka, 2020) ${ }^{[14]}$.

The first game was played in 1856 by the royal family of Thanjavur, Tamil Nadu. It is the most well-known in India. Badminton is an impulsive fast-paced sport that requires expertise, rapid impulses, sound judgment, alertness, and the talent to control the shuttle with one's wrist. The speed of the shuttle, in particular, will have no time to face the players must make quick and accurate decisions during the game (Shravan \& Vinod, 2020) ${ }^{[11]}$.

In current years, physical activity has not been the only factor in accomplishing greatest athletic performance in the world of sports. Personal abilities appear to influence the development of sports in addition to physical abilities and skills, as we know exciting means wanting to do something good and avoid doing something bad (Millni \& Montaseri, 2018) ${ }^{[9]}$. Sportspeople face numerous challenges and demands, including personal, social, emotional, and familial, as well as health-related ones. The role of sentiments such as nervousness, anger, and others in sports performance and adjustment is critical (Singh \& Bhardwaj, 2016) ${ }^{[12]}$.

Emotional intelligence is important and exciting for sports performance and concomitant adjustment. It is argued that the recognition of various emotions and emotional states, as well as assessments of their effects on various aspects of a sportsperson's behaviour, performance, and management of others as well as one's own emotions, are critical for success and adjustment in that field of sports and games. 
In education field a lot of investigators have investigated the idea of emotional intelligence (Chan, 2004; McPail, 2004; Esturgo-Deu and Sala-Roca, 2010) ${ }^{[3,8,4]}$ in relation to a sports field (Ajayi and Fatokun, 2008; Zizzi et al., 2003; Lane et al., 2010) $[1,16,6]$. In the literature, several definitions were proposed of emotional intelligence. Emotional intelligence was characterized by Mayer and Salovey (1997) ${ }^{[7]}$ as being the ability to help thoughts, grasp emotions and information so that emotional and intellectual development can be enhanced and emotions perceived and reached and regulated in a reflexive organization of emotions. Emotional intelligence, according to Bar-On (2005) ${ }^{[2]}$, is the capacity to know one's own emotions; understand one's own weak and dominant aspects; and express one's non-destroying emotions. Emotions can have an impact on intuitions, including acuity. Individuals, as example, will have a habit of to remark motivations in accordance with their sentiment. As a result a nervous basketball player may be more sensitive to the anxiety than the other types of data. Increase in the emotions by focusing on cues may increase the anxiety of the athlete to emphasis on the crowd (Vallerand \& Blanchard, 2000) ${ }^{[13]}$. According to Pavlenko et al. (2009) ${ }^{[10]}$, an enthusiastically constant person can easily get adjusted to the common changes in the environment without experiencing intense emotional reactions. Mental calmness and escape from fear and depression are symptoms of emotional stability (Hay \& Ashman, 2003) [5]. A person who is emotionally stable exhibits the features of emotional maturity, assurance and steadiness in their plan and affections; they face forward courageously to facts and situations without succumbing to occasionally changing mood.

\section{Aim of the Study}

The aim of this study is to evaluate intercollegiate badminton players' levels of emotional intelligence.

\section{Goals of the Study}

1. To measure responsive aptitude among inter-collegiate players.

2. To see the difference of emotional intelligence between male and female.

\section{Methodology}

\section{Research Design}

The research was primarily descriptive in nature. The survey method was used to collect consistent and precise information about the current state of the phenomenon and to reach valid conclusions.

\section{Research participants}

The sample consisted73badminton players. Of them 38 respondents are Male and 35 respondents are female. Probable specimen was used in this study instead of nonprobability sampling.

\section{Method of Data Collection}

Together primary and secondary method of data collection was used for this research. Primary data were collected Questioner method.

\section{Instruments}

Inventory for emotional intelligence by Dr. S.K. Mangal and Mrs. Shubhra Mangal was adopted to measure emotional intelligence of participants. This inventory was created in four capacities such as Intrapersonal and Interpersonal awareness and Management among the emotional intelligence with a $16+$ years old students. It has a total of 100 items. It is made up of four parts, each with 25 items.

\section{Statistical analysis}

In this study percentage method and frequency of respondents is used to classify the data on the basis of various dimensions.SPSS-22.0 for Windows software package was used for data processing.

\section{Data Analysis and Interpretation}

The following table no: 1 explains about the background of the badminton players. The frequency test was performed to show the percentage. Furthermore, the chi-square test was applied between gender of the badminton player and the anxiety, depression and stress among badminton players.

Table 1: Respondents' Background

\begin{tabular}{|c|c|c|c|}
\hline & & Frequency & Percent \\
\hline \multirow{4}{*}{ The Respondents' Age } & 19 to 21 years old & 42 & 57.5 \\
\hline & 22 to 24 years old & 20 & 27.3 \\
\hline & 25 and above & 11 & 15.2 \\
\hline & Total & 73 & 100.0 \\
\hline \multirow{3}{*}{$\begin{array}{l}\text { Gender of the } \\
\text { Respondents }\end{array}$} & Male & 38 & 52.1 \\
\hline & Female & 35 & 47.9 \\
\hline & Total & 73 & 100.0 \\
\hline \multirow{5}{*}{$\begin{array}{l}\text { Caste of the } \\
\text { Respondent }\end{array}$} & General & 24 & 32.9 \\
\hline & OBC & 24 & 32.9 \\
\hline & $\mathrm{SC}$ & 14 & 19.2 \\
\hline & ST & 11 & 15.1 \\
\hline & Total & 73 & 100.0 \\
\hline \multirow{5}{*}{$\begin{array}{l}\text { Religion of the } \\
\text { Respondent }\end{array}$} & Hindu & 74 & 64.4 \\
\hline & Muslim & 15 & 20.5 \\
\hline & Christian & 9 & 12.3 \\
\hline & Others & 2 & 2.7 \\
\hline & Total & 73 & 100.0 \\
\hline \multirow{3}{*}{$\begin{array}{l}\text { Family type of } \\
\text { Respondents }\end{array}$} & Joint & 22 & 30.1 \\
\hline & Nuclear & 51 & 69.9 \\
\hline & Total & 73 & 100.0 \\
\hline \multirow{3}{*}{$\begin{array}{l}\text { Domicile of } \\
\text { Respondents }\end{array}$} & Urban & 68 & 93.1 \\
\hline & Rural & 05 & 6.9 \\
\hline & Total & 73 & 100.0 \\
\hline \multirow{10}{*}{$\begin{array}{l}\text { Education level of } \\
\text { respondents }\end{array}$} & B.Com & 12 & 16.4 \\
\hline & BA & 12 & 16.4 \\
\hline & BBA & 9 & 12.3 \\
\hline & BCA & 7 & 9.6 \\
\hline & BPED & 8 & 11.0 \\
\hline & BSC & 1 & 1.4 \\
\hline & MA & 1 & 1.4 \\
\hline & MBA & 11 & 15.1 \\
\hline & MPED & 12 & 16.4 \\
\hline & Total & 73 & 100.0 \\
\hline
\end{tabular}

The above table no: 1 describes the background of the badminton players. Out of 73 respondents 57.5 percent of the badminton player's age cohort is $19-21$ years; 27.3 percent of the respondent's age cohort is $22-24$ years; and 15.2 percent of the respondents age cohort is 25 and above. It is clear from the above table that majority ( 57.5 percent) of the badminton players age cohort is $19-21$ years.

52.1 percent of the male respondents were participated in the present study and 47.9 percent of the female respondents participated. It is clear from the above table that majority (52.1 percent) of the male badminton players were participated the present study.

32.9 percent of the respondents belongs to Other Backward 
Classes (OBC) and general category; 19.2 percent of the respondents are from Scheduled Caste (SC); and 15.1 percent of the respondents are belongs to Scheduled Tribe (ST). It is clear from the above table that majority of the badminton players belongs to General (32.9 percent) and OBC (32.9 percent) category.

64.4\% of respondents Hindu religion; 20.5 percent of the respondents are from Muslim religion; 12.3 percent of the respondents belongs to Christian religion; and only 2.7 percent of the respondents are from other religion. The above table clearly shows that the majority (64.4 percent) of respondents are Hindus.

69.9 percent of those sampled are belongs to nuclear family members and 30.1 per cent of the defendants are from joint family. It is clear from the above table that 69.9 percent of the respondents are from nuclear family.

93.1 percent of perpetrators are from urban areas, while 6.9 percent are from rural areas. It is clear from the above table majority (93.1 percent) of the respondents are form urban area.

16.4 percent of the respondents are from B.Com, BA and MPED educational background; 15.1 percent of the respondents are from MBA; 12.3 percent of the respondents are from BBA; 11.0 percent of the respondents are from
BPED; 9.6 percent of the respondents are from BCA; and 1.4 percent of the respondents are from B.SC and MA. It clear from the above table that 16.4 percent of the respondents are from B.Com, BA, and MPED background.

Table 2: Emotional Intelligence Levels of Badminton Players

\begin{tabular}{|c|c|c|}
\hline Emotional Intelligence Level & Frequency & Percent \\
\hline $188 \&$ above $=$ Extremely High & 4 & 5.5 \\
\hline 170 to $187=$ High & 17 & 23.3 \\
\hline 151 to $169=$ Above Average & 50 & 68.5 \\
\hline 126 to $150=$ Average & 2 & 2.7 \\
\hline Total & 73 & 100.0 \\
\hline
\end{tabular}

The above table describes the level of emotional intelligence among badminton player. Out of 73 respondents, 68.5 percent of badminton players emotional intelligence level is above average; 23.3 percent of badminton players emotional intelligence level is high; 5.5 percent of badminton players emotional intelligence level is extremely high and only 2.7 percent of the badminton players emotional intelligence level is average. It is clear from the above table that majority $(68.5$ percent) of the respondents emotional intelligence level is above average.

Table 3: Association of Selected Variables with Emotional Intelligence

\begin{tabular}{|c|c|c|c|c|c|c|}
\hline Sl. No & Variable & Chi-Square Value & Degree of Freedom & Significant Level & Result & Testing Hypothesis \\
\hline 1 & Gender & 1.939 & 3 & .585 & Not Significant & Accepted \\
\hline 2 & Age & 5.123 & 6 & .528 & Not Significant & Accepted \\
\hline 3 & Education & 23.370 & 24 & .498 & Not Significant & Accepted \\
\hline
\end{tabular}

In order to see the association between selected variable namely gender, age and education with emotional intelligence of badminton players. It is found that there is no significant association between gender (.585), age (.528), and education (.498) of the elderly people with life satisfaction. Hence, the hypothesis, is accepted.

\section{Conclusion}

It is widely acknowledged that people with high emotional intelligence have better conceptual strength, more effective presentations, and superior leadership abilities. Indeed, having a high emotional intelligence appears to be the primary tool for adjusting sensations in tense situations. Sport psychology science has studied inspirational and mental aspects such as anxiety and emotional intelligence on how they are linked to sport performance and many of them have been outlined according to the achievement of goal theory. Emotional intelligence is a skill that influences optimistic consequences and behavior. Some suggestions for the future can be made. Teaching instructors, athletes, students, and fans on how to improve their sensitive aptitude can be a critical factor in foiling ferocity and inspiring ethical behaviour in sports.

\section{References}

1. Ajayi MA, Fatokun ALA. Effect of a six week emotional intelligence program on the sports performance of amateur athletes in Oyo state of Nigeria. Sport Research Intelligence sportive 2008.

2. Bar-On R. The Bar-On model of emotional-social intelligence. In P. Fernández-Berrocal and N Extremera (Guest Editors), Special Issue on Emotional Intelligence. Psicothema 2005, 17.

3. Chan DW. Perceived emotional intelligence and selfefficacy among Chinese secondary school teachers in
Hong Kong. Personality and Individual Differences 2004;36(8):1781-1795.

http://dx.doi.org/10.1016/j.paid.2003.07.007

4. Esturgo-Deu ME, Sala-Roca J. Disruptive behaviour of students in primary education and emotional intelligence, Teaching and Teacher Education 2010;26(4):830-837.

5. Hay I, Ashman AF. The Development of Adolescentse Emotional Stability and General Self-Concept: the interplay of parents, peers, and gender. International Journal of Disability, Development and Education 2003;50(1):77-91.

6. Lane AM, Devonport TJ, Soos I, Karsai I, Leibinger E, Hamar P. Emotional intelligence and emotions associated with optimal and dysfunctional athletic performance. Journal of Sports Science and Medicine 2010;9:388-392.

7. Mayer JD, Salovey P. What is emotional intelligence? (P. Salovey and D. J. Sluyter, Eds.) Emotional Development and Emotional Intelligence. New York: Basic Books 1997.

8. McPail K. An emotional response to the state of accounting education: Developing accounting students' emotional intelligence. Critical Perspectives on Accounting 2004;15(4-5):629-648. http://dx.doi.org/10.1016/S1045-2354(03)00050-9

9. Millni SM, Montaseri V. Relationship between Emotional Experiences of Sports and Emotional Intelligence with Self-Efficacy in Elite-Badminton Players. International Journal of Management and Applied Science 2018;4(9):29-31.

10. Pavlenko VS, Chernyi SV, Goubkina DG. EEG Correlates of Anxiety and EmotionalStability in Adult Healthy Subjects. Neurophysiology 2009;41(5):400-408.

11. Shravan T, Vinod S. Comparative Study of Reaction Time among Ball Badminton Players and Badminton 
Players of Osmania University, Hyderabad. International Conference on Enhancing Skills in Physical Education and Sport Science 2020 (pp. 291-292). Hyderabad: Rubicon Publications, London 2020.

12. Singh DP, Bhardwaj BK. Emotional Intelligence and Adjustment of Sports persons. The International Journal of Indian Psychology 2016;3(4):86-93. doi:18.01.066/20160304, ISBN: 978-1-365-26307-1

13. Vallerand RJ, Gawin LI, Halliwell WR. Effects of Zerosun competition on children "s intrinsic motivation and perceived competence". Journal of social Psychology 1983;126(4):465-470.

14. Wakradka M. Knee-injuries in Badminton: A Study. International Conference on Enhancing Skills in Physical Education and Sport Science 2020 (pp. 93-95). England: Rubicon Publications, London 2020.

15. WHO. Sixty-fifth World Health Assembly 2012. Geneva: World Health Organization 2012.

16. Zizzi SJ, Deaner HR, Hirschhorn DK. The relationship between emotional intelligence and performance among college baseball players. Journal of Applied Sport Psychology 2003;15(3):262-269. http://dx.doi.org/10.1080/10413200305390 